\title{
TECHNIQUES FOR TRACKING RFID TAGS IN A BIM MODEL
}

\author{
Anoop Sattineni \\ McWhorter School of Building Science, Auburn University, Auburn, Alabama, USA \\ anoop@auburn.edu \\ Salman Azhar \\ McWhorter School of Building Science, Auburn University, Auburn, Alabama, USA \\ salman@auburn.edu
}

\begin{abstract}
Academicians and industry professionals have demonstrated the use of Radio Frequency Identification (RFID) Tags in construction applications in the past few years. Recently building information modelling (BIM) technology is emerging as the industry standard in the architecture, engineering and construction (AEC) sector. This paper combines the two technologies to monitor the movement of RFID tags in a BIM environment. Real-time monitoring of RFID tags in a building information model is an improvement over other methods of tracking construction workers, equipment and materials on the jobsite. Strategies for combining the two technologies are explored. This method of monitoring can be used to improve the safety and productivity of construction workers on a construction jobsite. This technique of monitoring RFID tags can also be used to track equipment and construction materials on a job-site. Autodesk Revit BIM software environment was used for tracking RFID tags. The paper includes discussion about the choice of RFID tags available for this method of tracking.
\end{abstract}

\section{KEYWORDS: Radio Frequency Identification, Building Information Modelling, Tracking}

\section{INTRODUCTION}

The use of information technology applications in the architecture, engineering and construction (AEC) sector has been on the upswing over the past decade. The latest technology that is rapidly changing the landscape within the AEC sector is Building Information Modelling (BIM). Radio frequency identification (RFID) technology has gained popularity over the last two decades in several sectors and is considered to replace bar-code technology. RFID technology became popular for electronic toll collection on highways (K. Domdouzis et. al, 2007) during the 1990's but have since been used in various applications in the construction industry. This paper explores the possibility of combining RFID technology with BIM. An exploration of associated applications, specifically for safety and productivity in construction due to the combination of the two technologies is also presented. The science of RFID technology is briefly discussed in this paper. The use of BIM to track RFID tags in a 3 -D digital environment is presented. The choice of RFID tags and reader combinations is discussed. The various combinations in which RFID technology and an Autodesk Revit BIM model may be integrated are presented. 


\section{Radio frequency identification Technology}

RFID technology is employed to track objects, animals and people. The technology consists of an RFID tag that is attached to the object being tracked and a RFID reader that identifies the tag when it is within the range of the reader. An RFID tag transmits a signal through radio waves that in turn are received by an RFID reader, as shown in Figure 1. It is widely accepted that this technology will replace the use of Bar Codes for tracking purposes. An active RFID tag contains a battery and transmits a signal autonomously and may be tracked when it is within range of the reader. A passive tag does not have a battery but is activated when it is within range of the reader. The information collected by the reader in both cases may be kept in a database. This technology provides real-time information about the presence of an RFID tag within range of a reader and therefore also indicates the presence of the object that the tag is attached to.

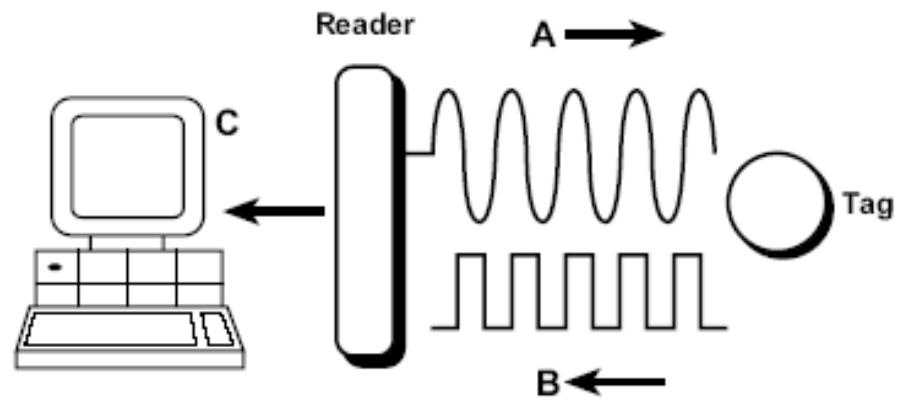

Figure 1: RFID Technology (Lake \& Jaselskis, 2000).

Academicians have explored the role of RFID tags in construction for some time now (E.J Jaselskis, T. El-Misalami, 2003). Studies done by D. Grau et. al (2009) have demonstrated the effectiveness of using RFID tags in tracking materials to improve productivity in construction. J. Song et. al (2006) have shown that the delivery of construction materials to the jobsite can be automated by the use of RFID tags. RFID tags have also been used to track tools on a construction site (A. Sattineni, G. Garrett, 2006). The case for real-time monitoring and its benefits to construction productivity have been made (R. Navon, 2005). RFID tags were used to monitor the safety of construction workers by D. Friedlos (2008) and W, Wu et. al (2010). RFID tags are also being proposed by C.H Ko (2009) to develop a building maintenance system.

\section{Building Information Modelling}

The National Building Information Model Standard (NBIMS) defines (Facility Information Council, 2007) a building information model as "A digital representation of physical and functional characteristics of a facility... As such it serves as a shared knowledge resource for information about a facility forming a reliable basis for decisions during its life-cycle from inception onward.” BIM technology improves the overall quality of design, provides better performing buildings requires fewer change orders during construction, allows the contractor to optimize the schedule and cost of the project and provides for efficient handover of the buildings to the owner for operations and maintenance. In the United States BIMs are 
increasingly making their way into the construction job trailers and are being used to improve the overall process of construction (McGraw Hill Construction, 2008).

All indications from the AEC industries are that the use of BIM in construction will continue to increase and significantly modify the practice of designing, constructing and maintaining future buildings. An industry survey report published by McGraw Hill Construction (2008) indicates that the use of BIM among contractors alone in the US would increase by $18 \%$ in just one year. The report also indicated that over $50 \%$ of all responders were using BIM. This indicates that the likelihood of future projects using BIM is very high.

\section{APPLICATIONS OFTRACKING RFID IN CONSTRUCTION}

It is globally accepted that safety risk to construction workers is very high. Over 2800 deaths have occurred in the U.K, over the past 25 years, as a result of construction activities (Health and Safety in Construction Industry, N.D). Accidents on construction sites are commonplace and tend to cause major havoc for the schedules and budgets of projects. Minimizing safety risk is an important concern for a construction company, regardless of its size. Studies done by Z. Riaz et. al (2006) demonstrate the lack of decline in safety accidents in construction and discuss how information and communication technology (ICT) may be used to reduce the accident rates. The technology proposed in this paper will use ICT to potentially minimize accidents in the construction industry.

Productivity of construction workers is directly related to the profitability of a construction project (Motwani et al, 1995). Supervision is an important aspect of measuring construction productivity. On a large construction site the use of RFID tags in a BIM model could alert the supervisor when a construction worker ventures outside the area where the work is being performed. The site supervisor may also use this information to direct construction workers to appropriate locations within a jobsite. As an example, the site supervisor might direct the nearest construction workers at a specific location to tend to a material delivery truck that has just arrived on the construction site.

Construction workers wearing an RFID tag may be represented in a 3-D model as shown in Figure 2. The location of construction workers may be colour coded to flag an unsafe condition or an instance in which the worker may have ventured outside the work area. This information can be used to remotely monitor worker safety and productivity by the construction site supervisor. In the example presented below the worker in red colour signifies an unsafe condition whereas the worker in blue colour signifies someone that is not at the appropriate location on the jobsite. 

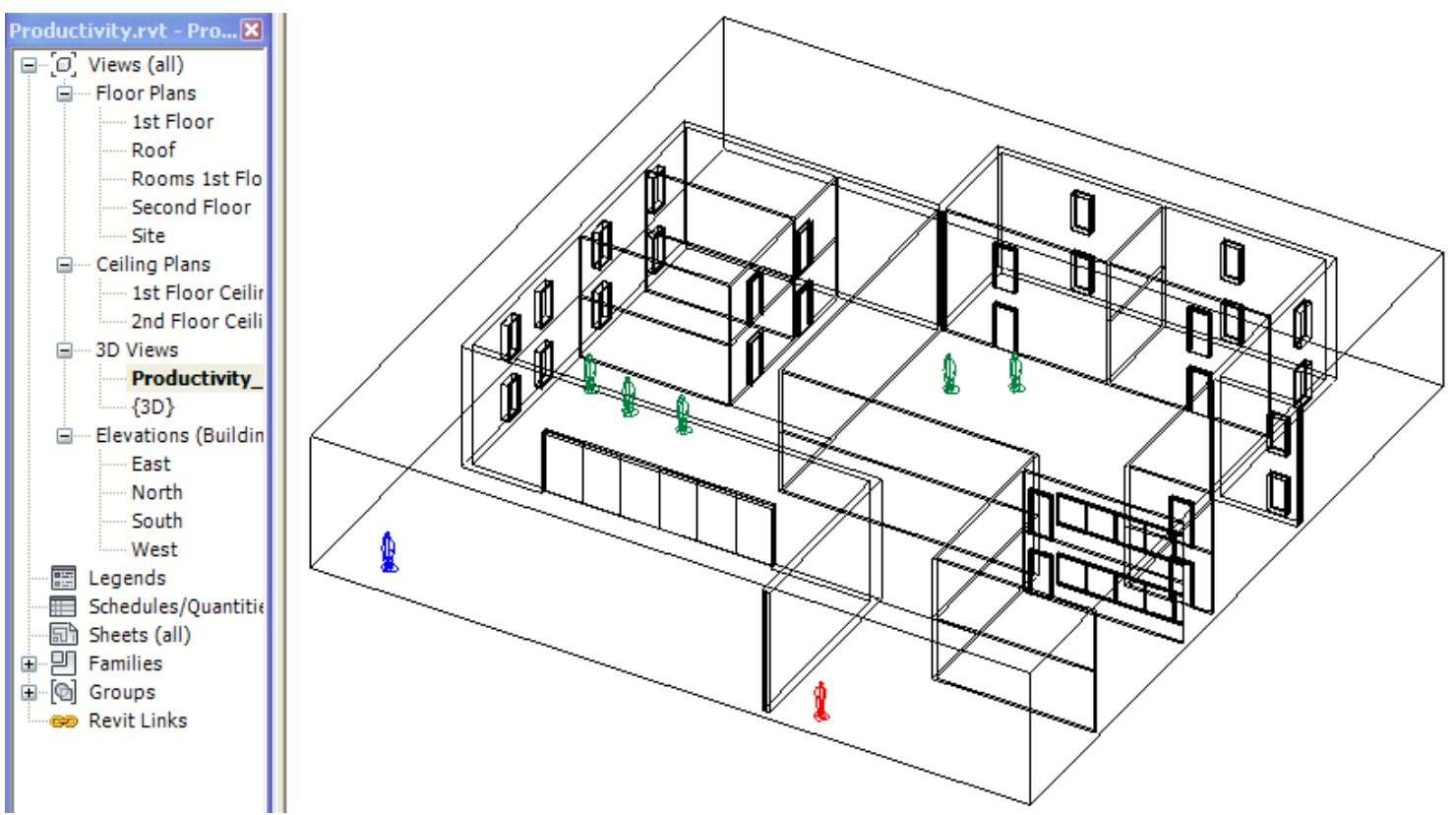

Figure 2. RFID Tag Tracking in an Autodesk Revit Model

\section{RIFD TRACKING AND BIM INTEGRATION TECHNIQUES}

Several types of RFID tags and reader combinations are commercially available to implement in the construction industry. Each tag and reader combination may be most applicable to certain situations. The discussion in this section identifies three broad categories of RFID tags and reader combinations and their possible uses in construction.

\section{RFID Tag Tracking Using Passive RFID Tags}

Passive RFID tags, shown in figure 3, are the least expensive tags commercially available. These tags require an external energy source to emit a radio signal. Unfortunately the external energy sources are bulky and cumbersome to move around very quickly in a construction environment. The range of these readers is extremely small compared to the active RFID tags and is a significant disadvantage in a construction environment.
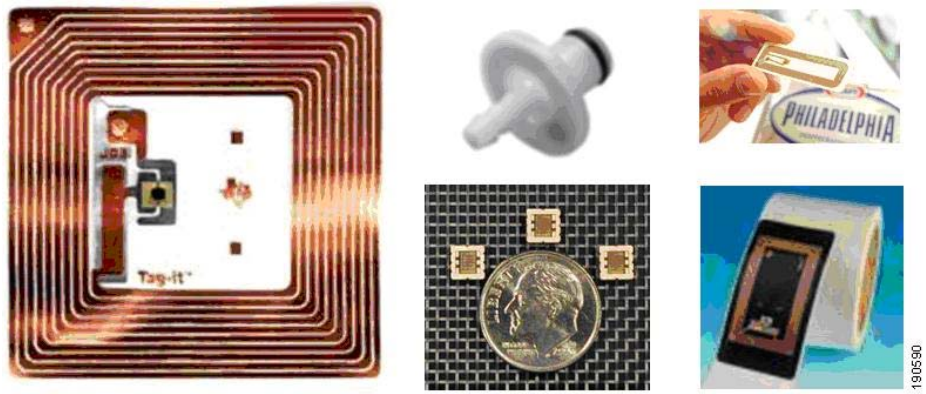

Figure 3. Passive RFID Tags (Cisco.com)

However, these tags are used with great effectiveness in the retail industry and are also used in identification cards that work in unison with automatic door opening technologies. These 
tags can be displayed in a BIM model as with any other RFID tags. The use of these tags may be most effective when it is possible to install passive RFID readers at control points such as entrances and exits.

\section{RFID Tag Tracking Using Active RFID Tags}

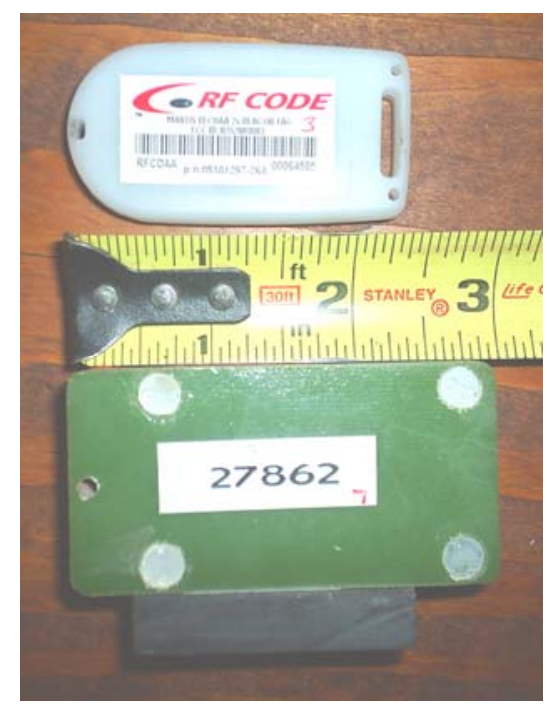

Figure 4. RF Code and Identec Active RFID tags

The most commonly reported tags used in research by construction academicians are active RFID tags. The major difference between active and passive RFID tags is that active tags have a built-in energy source such as a battery. Active RFID tags can be read from long ranges, as many as hundreds of feet. These tags are slightly larger than passive tags but are small enough to be used in a construction environment to track objects, people and materials. These RFID tags can be encapsulated in a plastic enclosure or a ruggedized enclosure, as shown in figure 4 . Some computation is generally necessary to approximately pinpoint the tags' location in a defined physical space since the range these tags may be up to several hundred feet. Several techniques are available to locate the tags with reasonable accuracy (J. Song et. al, 2006).

\section{RFID Tag Tracking Using Wi-Fi RFID Tags}

Another new technology that will play an important role in the use of RFID tags in the future is the Wi-Fi RFID tag. An active RFID tag requires the use of RFID specific infrastructure to read the signal transmitted called the RFID reader. The Wi-Fi RFID tag can be read by any 802.1b or 802.1g wireless access point device instead of a RFID reader. The Wi-Fi RFID tag connects to the wireless access point similar to a laptop computer. There exist two advantages of Wi-Fi RFID tags over other RFID tags. The first one is the range of distance a tag may be located to be picked-up by the reader is much higher with a wireless access point device. Another advantage is that expensive RFID tag readers are not required; the equipment costs in tracking these tags may be lower. This Wi-Fi tag shown in figure 5 has been used in the healthcare industry for tracking patient movement within a hospital. 


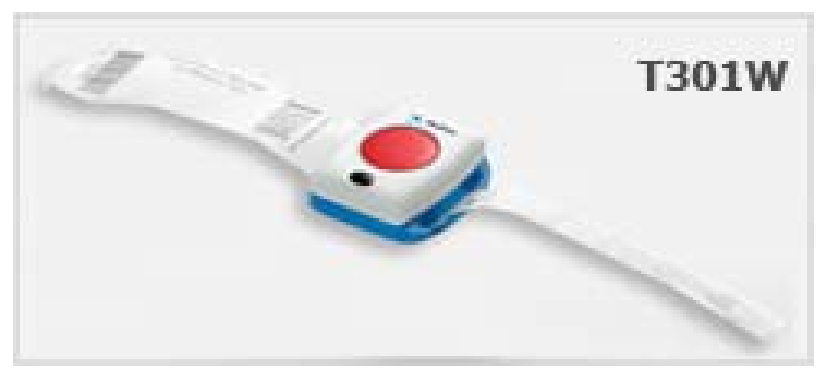

Figure 5. Wristband Wi-Fi RFID Tag (ekahau.com)

One disadvantage however is that technology will require additional methods such as checkpoint triggers for locating the tag within a confined space since wireless access devices have a much wider range than RFID tags. Checkpoint triggers or beacons, shown in figure 6 , are essentially the devices that can read a tag within a much smaller range. This technology may be suitable for construction sites where wireless networks are already available such as renovation projects. However, Wi-Fi RFID tags may be expensive to implement where wireless internet is not readily available, such as new construction project.

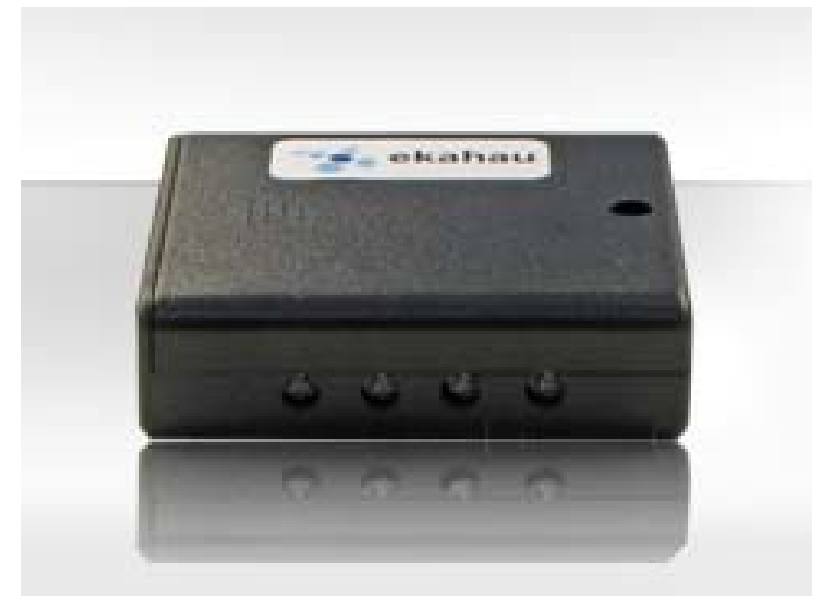

Figure 6. Location Beacon to determine precise co-ordinates for a Wi-Fi Tag (ekahau.com)

\section{Integrating RFID Tag Information into BIM Model}

RFID tags are tracked electronically and the information can be stored in a database used later. A typical RFID tag may be setup to be tracked at regular pre-set intervals such as 10 seconds or 1 second. Each RFID tag may be located by assessing the position of the last reader to track it. Regardless of the type of RFID reader and tag combination used some computing will be required to accurately assess the location of the tag within a pre-defined physical space. Once this information is obtained it may be translated into a CAD file or similar format so that it may be imported into the BIM model. 


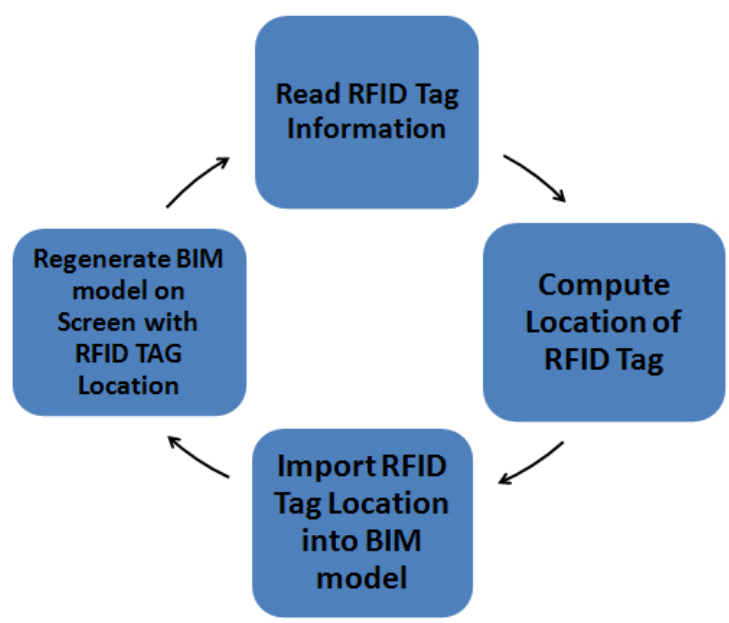

Figure 7. Location Beacon to determine precise co-ordinates for a Wi-Fi Tag (ekahau.com)

In certain applications such as ensuring the workers are at the designated location on a construction site, it would be more important to find the general location of a worker rather than the precise co-ordinates of the worker. Hence the location of the tag readers can be predecided at the specific control points such as site entrance, elevators, stairwell entrances or any location within the construction site. In the case of Wi-Fi RFID tags, additional location beacons shown in Figure 6 may be used to locate tags within a room or a zone of the construction site.

A BIM model that is compliant with the Industry Foundation Classes (IFCs) inherently adheres to a common data model. Most BIM software allows an external file to be imported and overlaid on the BIM model as shown in figure 2. The RFID data described above can be imported into the BIM model and displayed. The resulting model can be monitored by the construction project manager or superintendent to ascertain that construction workers are at the proper location. Some additional modules within the BIM model may be needed, to set up automatic triggers to highlight workers that are out of position.

Anytime the movement of people is tracked, privacy concerns of that information exist. These concerns must be addressed before the technology can be fully implemented. The tracking information must be used solely to monitor construction safety and productivity. The storage of the information must be limited to a few days only so that the data is not misused at a later time. It must be communicated to the construction workers that the proposed technology will enhance their safety provide for a better work environment.

\section{CONCLUSIONS}

RFID technology is used to track and locate objects and people in a pre-defined physical space. A BIM model, among its many other uses, is also used to represent a physical space in three dimensions. The combination of these two technologies allows construction companies to monitor issues such as construction worker safety and productivity. This combination could also be used to track the movement of materials and equipment within a jobsite. The visualization of an RFID tag in BIM model can be used to improve the overall conditions on 
a construction jobsite. This combination will undoubtedly lead to several innovations in the construction industry.

\section{REFERENCES}

A. Sattineni and G. Garrett, Using Radio Frequency Identification Technology (RFID) for Tracking Tools on a Construction Job Site. International Journal of Technology, Knowledge and Society Volume 2, Issue 4, 2006

C.H Ko, RFID-Based Building Maintenance System. Automation in Construction, 18, 2009, $275-284$

C. Lake, E. Jaselskis (2000), RFID Applications for Owners and Contractors, Proc. Construction Industry Institute Annual Conf., Nashville, Tennessee, pp.7-24.

D. Grau, C.H. Caldas, C.T. Haas, P.M. Goodrum, J. Geong, Assessing the impact of materials tracking technologies on construction craft productivity. Automation in Construction, 18, 2009, 903 - 911

D. Friedlos, RFID Improves Safety, Efficiency of Brisbane Tunnel Construction, [Online] http://www.rfidjournal.com/article/view/4137, June, 2008 (Retrieved: 25, August, 2009)

E.J Jaselskis, T. El-Misalami, Implementing Radio Frequency Identification in the Construction Process. Journal of Construction Engineering and Management. Volume 129, Issue 6, 2003, 680-688

Health and Safety in Construction Industry [Online] http://www.hse.gov.uk/construction/ (Retrieved: 25, August, 2009)

J Song, CT Haas, C Caldas, E Ergen, B Akinci, Automating the task of tracking the delivery and receipt of fabricated pipe spools in industrial projects. Automation in Construction, 15, 2006, $166-177$

J. Song, C.T. Haas, C.H. Caldas, A proximity-based method for locating RFID tagged objects, Advanced Engineering Informatics, Volume 21, Issue 4, 2007, Pages 367-376

J. Motwani, A. Kumar, M. Novakoski, Measuring construction productivity: a practical approach Vol. 44 No. 8, 1995, pp. 18-20, (c) MCB University Press, 0043-8022

K. Domdouzis, B. Kumar, C. Anumba, Radio-Frequency Identification (RFID) applications: A brief introduction, Advanced Engineering Informatics, Volume 21, Issue 4, 2007, Pages 350-355

M. Abderrahim, E. Garcia, R. Diez, C. Balaguer, A mechctronics security system for the construction Site. Automation in Construction, 14, 2005, 460 - 466

McGraw Hill Construction, 2008 BIM Smart Market Report, [Online] http://www.buildingsmartalliance.org/pdfs/mhc_bim_smartmarket.pdf (Retrieved: 25, August, 2009) 
R. Navon, Automated project performance control of construction projects. Automation in Construction, 14, 2005, 467 - 476

Z. Riaz, D.J. Edwards, A. Thorpe, SightSafety: A hybrid information and communication technology system for reducing vehicle/pedestrian collisions. Automation in Construction, 15, 2006, $719-728$

W. Wu, H. Yang, D.A.S. Chew, S. Yang, A.G.F. Gibb, Q. Li, Towards an autonomous realtime tracking system of near-miss accidents on construction sites, Automation in Construction, Volume 19, Issue 2, March 2010, Pages 134-141 